\title{
Contribuições e desafios das práticas corporais e meditativas à promoção da saúde na rede pública de atenção primária do Município de São Paulo, Brasil
}

\section{Contributions and challenges associated with bodily practices and meditation for health promotion in the public primary care system in the city of São Paulo, Brazil}

\section{Contribuciones y desafíos de las prácticas corporales y meditativas a la promoción de la salud en la red pública de atención primaria del municipio de São Paulo, Brasil}

Ana Tereza Costa Galvanese 1

Nelson Filice de Barros 2

Ana Flávia Pires Lucas d'Oliveira 1

\section{Resumo}

O artigo apresenta análise das contribuições e os desafios das práticas corporais e meditativas à promoção da saúde na rede pública de atenção primária. A pesquisa qualitativa foi desenvolvida em 16 unidades de saúde do Município de São Paulo, Brasil, por meio de entrevistas de 29 profissionais e 36 praticantes, e observação participante de 31 práticas, entre Tai Chi, Lian Gong, Qi Gong, Yoga, Capoeira, Danças, Meditação, Relaxamento, Consciência e Percepção Corporal. Houve melhora de dores articulares, mobilidade, equilíbrio, memória, depressão e ansiedade, e maior facilidade ao lidar com condições crônicas. Tais contribuições são relacionadas ao favorecimento da autonomia dos praticantes, pela construção de referências de saúde por intermédio do autoconhecimento; à união entre promoção e cuidado terapêutico nas abordagens; e ao apoio ao acesso a bens culturais e espaços de cidadania. Os desafios identificados são a precariedade na integração com as demais ofertas dos serviços de saúde, a carência de supervisão e avaliação, assim como o predomínio de uma cultura setorial na saúde.

Conhecimentos, Atitudes e Prática em Saúde; Terapias Complementares; Meditação

\author{
Correspondência \\ A. T. C. Galvanese \\ Departamento de Medicina Preventiva, Faculdade de Medicina, \\ Universidade de São Paulo. \\ Av. Dr. Arnaldo 455, São Paulo, SP 01246-903, Brasil. \\ anagalvanese@usp.br \\ 1 Faculdade de Medicina, Universidade de São Paulo, São Paulo, \\ Brasil. \\ 2 Faculdade de Ciências Médicas, Universidade de Campinas, \\ Campinas, Brasil.
}




\section{Introdução}

O presente trabalho se propõe a analisar as contribuições e desafios das práticas corporais e meditativas à promoção da saúde em um contexto da atenção primária em saúde no Sistema Único de Saúde (SUS).

As Medicinas Tradicionais e Complementares (MTC) 1, também denominadas Práticas Integrativas e Complementares (PIC), constituem um amplo conjunto de práticas de atenção à saúde que abrange tradições de cuidado de diferentes culturas, bem como práticas complementares que não fazem parte destas tradições e tampouco estão totalmente incorporadas aos sistemas de saúde.

A incorporação dessas medicinas e práticas aos sistemas nacionais de saúde é objeto de uma estratégia da Organização Mundial da Saúde (OMS) 1, e corresponde, no Brasil, à Política Nacional de Práticas Integrativas e Complementares (PNPIC) 2 2. Essa, por sua vez, resulta de longa trajetória com a contribuição de movimentos populares de saúde, profissionais, gestores e pesquisadores. Um de seus fundamentos é a coexistência de diferentes racionalidades médicas na sociedade contemporânea em que a racionalidade ocidental, orientada basicamente pelo paradigma da normalidade/patologia, está ligada à priorização de abordagens medicamentosas e cirúrgicas, enquanto as medicinas ditas holísticas, referidas ao paradigma da vitalidade, comportam uma multiplicidade de outras práticas de cuidado e autocuidado 3. Atualmente, a PNPIC abrange três sistemas médicos complexos e duas terapêuticas, respectivamente: Medicina Tradicional Chinesa; Homeopatia; Medicina Antroposófica; Plantas Medicinais e Fitoterapia; e Termalismo Social. Contudo, suas modalidades mais disseminadas na atenção primária são as práticas corporais e meditativas, compostas por recursos terapêuticos da Medicina Tradicional Chinesa e por um elenco diversificado de práticas complementares 2 ainda pouco discutidas e exploradas 4 .

O campo da promoção da saúde foi organizado a partir dos movimentos que impulsionaram a I Conferência Internacional sobre Cuidados de Saúde de Alma-Ata, em 1978. Desde então, a elaboração de iniciativas desenvolvidas em alguns países e o aprofundamento de experiências locais por meio de conferências internacionais resultaram em documentos norteadores 5 , destacadamente a Carta de Ottawa 6, de 1986, que definiu a promoção de saúde como "processo de capacitação da comunidade para atuar na melhoria de sua qualidade de vida e saúde, incluindo maior participação no controle deste processo" e situou a saúde como "um recurso para a vida, e não como objetivo de viver". Em 1998, foram sistematizados sete princípios norteadores da promoção da saúde: o empoderamento; a participação social; o holismo; a intersetorialidade; a equidade; a sustentabilidade; e as ações multiestratégicas 7. No Brasil, essas referências subsidiaram a elaboração da Política Nacional de Promoção da Saúde (PNPS), formalizada em 2006 e continuamente atualizada 8 , com a tarefa de se constituir em política transversal, integrada e intersetorial.

Na PNPS, a valorização das PICs consta nos objetivos, porém suas práticas corporais e meditativas têm uma inserção ambígua: práticas corporais e atividades físicas constituem, juntas, um tema prioritário, e a associação dos dois termos encobre suas diferenças epistemológicas, de concepção e de prática da promoção de saúde.

"Atividades físicas" é uma expressão historicamente associada ao paradigma biologizante, e "práticas corporais" refere-se a um conceito em construção, que abarca a perspectiva do cuidado ampliado, ao integrar às abordagens do corpo suas dimensões culturais, sociais, lúdicas, de autoconhecimento e de crítica aos modos de vida contemporâneos ${ }^{9}$. As práticas corporais das PICs correspondem a essa concepção e acrescentam a perspectiva da unicidade corpo-mente. Práticas meditativas estão presentes nas PICs, têm origens diversificadas e são passíveis de diferentes definições. Caracterizam-se por procedimentos regulares e definidos na produção de relaxamento psicofísico e lógico - entendido como ausência de expectativa em relação ao processo - atenção a um foco determinado, e aprendizado voltado à prática autônoma 10 . Não há menção a essas práticas na PNPS.

Face ao contraste entre a expansão das práticas corporais e meditativas e sua fragilidade institucional 4, parte-se da inter-relação entre políticas e práticas de saúde, com contribuições e olhares diferenciados para as necessidades de saúde e, potencialmente, tensões entre elas 11. O estudo aqui apresentado focaliza as práticas de saúde no seu cotidiano na atenção primária à saúde. 


\section{Métodos}

Trata-se de pesquisa qualitativa 12 realizada em duas regiões administrativas de uma Coordenadoria Regional de Saúde do Município de São Paulo, Brasil. O funcionamento como porta de entrada do SUS foi o critério adotado para a seleção dos serviços escolhidos, mesmo sem integrar formalmente a rede de atenção primária. Um levantamento prévio indicou a existência de 67 práticas grupais corporais e meditativas distribuídas em 32 serviços. Desses, 16 participaram da pesquisa, sendo 12 unidades básicas de saúde (UBS), sete das quais vinculadas a Núcleos de Apoio à Saúde da Família (NASF); dois Centros de Convivência e Cooperativa (CECCO); um Centro de Saúde Escola (CSE); e um Centro de Testagem e Aconselhamento/Serviço de Assistência Especializada em Doenças Sexualmente Transmissíveis e AIDS (CTA/SAE DST/AIDS). Para a escolha das atividades procuramos abranger a diversidade das práticas encontradas, pressupostas pela diversidade dos nomes; e observar mais de uma prática entre aquelas mais frequentes, para identificar diversidades ou homogeneidades (Tabela 1). Realizamos a produção dos dados de outubro de 2013 a setembro de 2014, por meio de imersão por até 15 dias em cada serviço, com observação participante de 31 práticas corporais e meditativas em grupo (Tabela 2), e entrevistas semiestruturadas com 29 profissionais (Tabela 3) e 36 usuários praticantes (Tabela 4). A triangulação de métodos de produção dos dados 13 teve por finalidade compreender como essas práticas são produzidas, vivenciadas e apropriadas pelos diferentes sujeitos envolvidos no cuidado.

Optamos pela observação de uma sessão por prática, em função da extensão do material de campo. Cada observação teve duração de duas horas, com registros produzidos após o seu término. Os diários de campo foram compostos por notas descritivas e reflexivas, as primeiras realizadas mediante roteiro elaborado para descrever os enquadres, ambientes e condução das práticas; as práticas em seus aspectos técnicos, materiais e comunicativos; e os vínculos interpessoais e demais desdobramentos de cada encontro. A perspectiva da observadora, caracterizada pela formação de terapeuta ocupacional com experiência em abordagens corporais, guiou a priorização desses elementos como meios terapêuticos 14 constitutivos dessas atividades. As notas descritivas e reflexivas visaram à produção de uma descrição densa 15, a fim de captar as relações entre experiência corporal de autoconhecimento e promoção da saúde 16 nas práticas analisadas.

As entrevistas com os profissionais foram previamente agendadas e tiveram por finalidade captar dimensões coletivas das práticas, em narrativas e reflexões dos seus protagonistas 17 . Os critérios de escolha dos entrevistados foram a diversidade das abordagens e profissões dos ministrantes, além da disponibilidade para a entrevista. $\mathrm{O}$ roteiro utilizado abordou formação e trabalho corporal no cotidiano dos entrevistados; referências conceituais adotadas nas práticas; necessidades de saúde e benefícios percebidos; e articulações com outras ofertas de cuidado.

As entrevistas com os usuários foram realizadas mediante convite ao final de cada prática observada e guiadas por roteiro que contemplou motivações, necessidades de saúde e desdobramentos das práticas na vida cotidiana dos praticantes, bem como suas relações com os demais modos de cuidado oferecidos no SUS. Previstas inicialmente como entrevistas individuais, parte delas foi realizada em forma de entrevista em grupo 18 para se adaptar às disponibilidades dos entrevistados, o que trouxe informações sobre as relações internas aos grupos e semelhanças e diferenças entre os participantes.

A análise foi inspirada no referencial fenomenológico existencial, na perspectiva denominada Analítica do Sentido 19. A compreensão da realidade como fenômeno pressupõe o reconhecimento das limitações do pesquisador por fazer parte do fenômeno que deseja conhecer, e a relatividade e o caráter provisório das respostas às indagações de pesquisa. A concepção de inseparabilidade entre o "ser" e o "aparecer" do fenômeno diferencia essa abordagem metodológica dos métodos que trabalham com a ideia de representação. Entende-se por sentido o rumo ou direção para onde tende o fenômeno. A aproximação com os sentidos das práticas foi empreendida por meio da atenção para aquilo de que se cuida; os modos de cuidado; e de atenção com este cuidar. Os conceitos de habitus 20 e de modos somáticos de atenção 21 foram aportes teóricos para a análise.

O interesse pelo tema foi motivado pela trajetória dos autores em saúde coletiva, terapia ocupacional e PICs na atenção primária à saúde, e o protocolo norteador da pesquisa se apoia no corpo de conhecimentos destes campos para abordar as práticas na perspectiva da complexidade da atividade humana como ação no mundo. $\mathrm{O}$ artigo apresenta parte dos resultados de pesquisa de doutorado. 


\section{Tabela 1}

Práticas corporais e meditativas informadas pelos serviços e observadas.

\begin{tabular}{|c|c|c|c|}
\hline Denominação das práticas & Informadas pelos serviços & Suspensas & Observadas \\
\hline Tai Chi Pai Lin & 14 & - & 4 \\
\hline Tai Chi e Dança Circular & 1 & - & - \\
\hline Tai Chi com Dança & 1 & - & 1 \\
\hline Lian Gong & 9 & - & 4 \\
\hline Qi Gong & 2 & - & 1 \\
\hline Qi Gong e Roda de Conversa & 2 & - & 1 \\
\hline Dao Yin & 1 & 1 & - \\
\hline Dança Circular & 10 & - & 4 \\
\hline Dançando com Saúde & 1 & 1 & - \\
\hline Dança & 1 & - & 1 \\
\hline Dança Sênior & 1 & - & 1 \\
\hline Dança Cigana & 1 & - & - \\
\hline Meditação & 4 & - & 3 \\
\hline Meditação e Relaxamento & 1 & - & 1 \\
\hline Tai Chi com Meditação & 1 & - & 1 \\
\hline Relaxamento & 1 & - & 1 \\
\hline Atividades Físicas e Práticas Meditativas & 1 & - & - \\
\hline Yoga & 3 & 1 & 1 \\
\hline Hatha Yoga & 1 & - & 1 \\
\hline Yoga e Meditação & 1 & - & - \\
\hline Capoeira & 3 & 2 & 1 \\
\hline Capoeira e Cultura Afro-brasileira & 1 & - & 1 \\
\hline Práticas Corporais & 1 & - & - \\
\hline Grupo de Práticas Corporais & 1 & - & 1 \\
\hline Grupo Corporal & 1 & - & 1 \\
\hline Percepção Corporal & 1 & - & 1 \\
\hline Corpo e Cotidiano & 1 & - & 1 \\
\hline Aliviando as tensões & 1 & - & - \\
\hline Total & 67 & 5 & 31 \\
\hline
\end{tabular}

O projeto foi aprovado nos Comitês de Ética da Faculdade de Medicina da Universidade de São Paulo (parecer 377.267, de 29 de agosto de 2013) e da Prefeitura do Município de São Paulo (parecer 470.025, de 27 de novembro de 2013). As entrevistas foram realizadas mediante assinatura dos Termos de Consentimento Livre e Esclarecido, com garantia do anonimato dos entrevistados.

\section{Resultados}

A maior presença de praticantes em todos os grupos foi de mulheres maiores de 40 anos, de origens étnico-raciais diversas, com vínculos precários de trabalho ou sem inserção no mercado profissional e com responsabilidade pelas tarefas domésticas. Alguns grupos apresentaram maior paridade entre mulheres e homens idosos, outros foram formados por trabalhadoras jovens, e poucos com mulheres e homens de diversas faixas etárias e profissões.

Os motivos que os levaram a praticar foram variados: dores articulares, com casos de insucesso em tratamentos anteriores; limitações de mobilidade; dificuldades de equilíbrio; problemas de memória; tristeza e solidão; insônia; ansiedade; depressão; e indicação das práticas por profissionais de saúde, para o controle de doenças e agravos não transmissíveis. 
Tabela 2

Práticas corporais e meditativas observadas e contexto da observação.

\begin{tabular}{|c|c|c|c|c|c|c|c|c|}
\hline Práticas observadas & $\begin{array}{l}\text { UBS/CSE } \\
\text { interna }\end{array}$ & UBS/Igreja & $\begin{array}{c}\text { UBS/ } \\
\text { Biblioteca }\end{array}$ & UBS/Escola & UBS/CEU & UBS/Praça & CECCO & Total \\
\hline Tai Chi Pai Lin & 2 & 1 & - & - & - & - & 1 & 4 \\
\hline Dança Circular & 1 & 1 & - & - & 1 & - & 1 & 4 \\
\hline Lian Gong & 1 & 2 & 1 & - & - & - & - & 4 \\
\hline Meditação & 1 & - & 1 & - & - & - & 1 & 3 \\
\hline Práticas Corporais & - & - & - & 1 & - & 1 & - & 2 \\
\hline Yoga/Hatha Yoga & - & - & - & - & - & - & 2 & 2 \\
\hline $\begin{array}{l}\text { Capoeira/Capoeira e Cultura Afro- } \\
\text { brasileira }\end{array}$ & - & - & - & 1 & - & - & 1 & 2 \\
\hline Relaxamento & 1 & - & - & - & - & - & - & 1 \\
\hline Qi Gong & 1 & - & - & - & - & - & - & 1 \\
\hline Tai Chi com Dança & 1 & - & - & - & - & - & - & 1 \\
\hline Tai Chi e Meditação & 1 & - & - & - & - & - & - & 1 \\
\hline Meditação e Relaxamento & 1 & - & - & - & - & - & - & 1 \\
\hline Qi Gong e Roda de Conversa & - & 1 & - & - & - & - & - & 1 \\
\hline Corpo e Cotidiano & 1 & - & - & - & - & - & - & 1 \\
\hline Percepção Corporal & - & - & - & - & - & - & 1 & 1 \\
\hline Dança Sênior & - & - & - & - & - & - & 1 & 1 \\
\hline Dança & 1 & - & - & - & - & - & - & 1 \\
\hline Total & 12 & 5 & 2 & 2 & 1 & 1 & 8 & 31 \\
\hline
\end{tabular}

CECCO: Centro de Convivência e Cooperação; CEU: Centro Educacional Unificado; CSE: Centro de Saúde Escola; UBS: unidade básica de saúde.

\section{Tabela 3}

Práticas corporais e meditativas: profissionais entrevistados na pesquisa.

\begin{tabular}{|c|c|c|c|c|}
\hline Profissão & $\begin{array}{c}\text { Responsáveis pelos } \\
\text { grupos }\end{array}$ & $\begin{array}{c}\text { Coordenadores da } \\
\text { política e da formação }\end{array}$ & $\begin{array}{c}\text { Com formação e sem } \\
\text { grupos }\end{array}$ & Entrevistados \\
\hline Terapeuta ocupacional & 12 & & & 6 \\
\hline Psicólogo & 6 & 2 & & 4 \\
\hline Fisioterapeuta & 4 & & & 3 \\
\hline Agente comunitário de saúde & 3 & & & 2 \\
\hline Assistente social & 2 & & 1 & 2 \\
\hline Dentista & 2 & & & 2 \\
\hline Fonoaudiólogo & 2 & & 1 & 2 \\
\hline Médico & 1 & 1 & & 2 \\
\hline Educador físico & 2 & & & 1 \\
\hline Voluntário & 2 & & & 1 \\
\hline Assistente administrativo & 1 & & & 1 \\
\hline Auxiliar de enfermagem & 1 & & & 1 \\
\hline Educador de saúde pública & 1 & & & 1 \\
\hline Nutricionista & 1 & & & 1 \\
\hline Técnico de enfermagem & 1 & & & - \\
\hline Total & 41 & 3 & 2 & 29 \\
\hline
\end{tabular}


Práticas corporais e meditativas: usuários entrevistados na pesquisa.

\begin{tabular}{lccccc}
\hline Práticas com usuários entrevistados & \multicolumn{2}{c}{ Contexto } & \multicolumn{2}{c}{ Entrevistados } \\
& UBS/CSE & CECCO & Igrejas & Escolas \\
\hline Tai Chi Pai Lin & 6 & - & 4 & - & 10 \\
Lian Gong & 1 & - & 5 & - & 6 \\
Dança Circular & - & 4 & - & - & 4 \\
Tai Chi com Meditação & 3 & - & - & - & 3 \\
Tai Chi com Dança & 3 & - & - & - & 3 \\
Capoeira & - & 2 & - & - & 2 \\
Meditação & 2 & - & - & - & 2 \\
Qi Gong & 2 & - & - & - & 2 \\
Corpo e Cotidiano & 1 & - & - & - & 1 \\
Grupo Corporal & - & - & - & 1 & 1 \\
Relaxamento & 1 & - & - & - & 1 \\
Qi Gong & 1 & - & - & - & 1 \\
Total & 20 & 6 & 9 & 1 & 36 \\
\hline
\end{tabular}

CECCO: Centro de Convivência e Cooperação; CSE: Centro de Saúde Escola; UBS: unidade básica de saúde.

As razões que motivaram os participantes a persistir nas práticas foram também diversas: a melhora total ou parcial das dores articulares, da mobilidade, do equilíbrio e da memória, referidas principalmente por idosos; e de sintomas de depressão e ansiedade, com melhor qualidade do sono, independentemente da faixa etária. Praticantes com comprometimentos psíquicos e cognitivos fizeram mais referência à ampliação de suas redes de convivência, já os que ingressaram nos grupos por indicação devido ao diabetes e à hipertensão arterial relataram maior equilíbrio nos parâmetros de controle destas condições e, em alguns casos, diminuição da necessidade de uso de fármacos.

A primeira particularidade a ser destacada refere-se a relatos de ajustes e modificações que praticantes promoveram em suas vidas, com base em percepções de si experimentadas nas práticas. Narrativas fazem referência a seus processos de reconhecimento e tomada de posição frente a situações por eles relacionadas à origem das suas enfermidades.

Uma praticante diz: "Fui me reconhecendo, percebi quando dava a dor, se um pé fica com o peso que nemo outro pé (...) a colocar o balde mais alto para não doer o joelho"; a outra observa: "Até pra passar pano na casa, a gente tem que ter postura"; e a terceira emenda: "As meninas do laboratório falam: 'nossa! Você tem um jeito todo chique e importante de passar o pano' [e demonstra seu 'jeito' inclinando-se à frente com o apoio de um joelho flexionado e alinhado com o pé]" (Grupo Corpo e Cotidiano, atividade interna, unidade D).

Outros relatos fazem referência à aquisição de uma qualidade de atenção que possibilitou mudar seus modos de lidar consigo, com os outros e com os seus contextos de vida.

"Sou uma pessoa muito agitada, muito, muito. Agora eu consigo, com a meditação, parar, eu consigo recuar. Porque quem é muito agitado e quer resolver de qualquer jeito não resolve da melhor maneira, né? Você tem que esperar o outro querer e decidir também (...) por ser uma pessoa muito agitada, às vezes a gente 'atropela' (...) acho que eu consigo, agora, enxergar e analisar. Meditar faz a gente se enxergar como ser humano" (EBM, Meditação, atividade interna, unidade R).

A oferta de oportunidades de percepção e apropriação de si, de seus modos de relação com o outro e com o contexto, observada independentemente da linha de trabalho adotada, caracterizou-se por: serenidade da comunicação ao se dispor corporalmente no espaço; cuidado com a respiração ou com os ritmos do corpo; convites à percepção corporal na pausa ou no movimento; uso do tempo, do silêncio ou da música; e sinergia de movimento com os participantes.

Outra característica observada nas práticas é a incorporação de momentos de conversa, informais ou previstos nos encontros. Eventualmente pôde-se observar a oferta de acesso, aos praticantes, às referências conceituais de algumas vertentes de trabalho adotadas. 
"[a profissional propõe] em roda, alguns minutos de silêncio, a fim de 'colocar o corpo dentro da sala' (sic) (...) os praticantes falam sobre suas experiências e desafios de praticar em casa. (...) Ela lê um texto curto que fala dos cinco movimentos cíclicos da natureza, e propõe que o grupo comente. Alguns fazem analogias com a vida na roça, regida pelas estações; outros, com a onda de frio daqueles dias, que 'deixa a gente encolhida' (sic). Quando todos terminam de falar [ela] estabelece ligação entre os argumentos trazidos pelos participantes e o contínuo movimento de expansão e contração, 'o yin e o yang' (sic), e relaciona vida, saúde e movimento" (Grupo Lian Gong, igreja, unidade $\mathrm{G}$ ).

Modos de condução das práticas distanciados e sem comunicação entre profissionais e praticantes também foram observados, ainda que mais raramente. Nessas situações, os primeiros executaram as práticas sem estabelecer comunicação corporal ou verbal, algumas vezes de costas para os demais presentes, e os segundos pareceram imitá-las de acordo com o que conseguiram captar.

A segunda particularidade refere-se à união entre promoção e cuidado terapêutico no âmbito das práticas, face à integração ou fragmentação dos cuidados em relação às demais ofertas dos serviços.

Idosos que relataram manejar mais facilmente suas dificuldades a partir das práticas sugeriram também que referências ali adquiridas se tornaram recurso para lidar mais confortavelmente com a variabilidade das suas situações de saúde.

"Eu percebo uma melhora muito grande, sabe? Melhora a coluna. Quando entram as férias, [a instrutora recomenda]: 'faz em casa, não fica sem fazer'; e às vezes, a gente, pra fazer sozinha, não faz. E aí eu começo sentir qualquer coisa, e... 'não, agora eu vou fazer', e eu melhoro, sabe? Melhoro bastante.... nossa! Fico boa, passo bem, não sinto dores, sabe?" (EDL, Tai Chi Pai Lin, centro de convivência, unidade F).

Outros relataram experimentar, por meio das práticas, uma integridade corpo-mente capaz de possibilitar um olhar distanciado para seus problemas cotidianos.

"A gente fica com a mente diferente. Porque não fica pensando só naqueles problemas que a gente já passou, naqueles que tá passando, então você consegue se desligar de alguns problemas e se voltar um pouco para si, porque às vezes nós nos esquecemos, deixamos de movimentar nosso corpo, de usar nossa mente" (EAC, Lian Gong, igreja, unidade V).

Nos dois exemplos mostrados, identifica-se a construção de referências próprias de saúde; no segundo, o relato do praticante sugere também que a experiência de praticar potencializou mudanças no seu modo de se relacionar com os eventos da vida.

Entre os praticantes que relataram ganhos ao se empenhar com regularidade nas práticas, há os que foram beneficiados pela integração dos cuidados na unidade de saúde.

"No comę̧o eu ainda sentia dores, né? Eu andava com bengala, tenho artrose nos dois joelhos (...) aí eu comecei a praticar (...) e eu aplico [recebe aplicações de medicamento] uma vez por semana (...). A [médica da UBS] indica pra gente fazer o Qi Gong, ela indica muitos pacientes dela; é que eu, como passo pela psicóloga [da UBS], então ela que me indicou, mas a doutora apoia (...). Resolveu bastante pra mim; depois de uns três meses eu deixei a bengala" (EL, Qi Gong, atividade interna, unidade T).

Mas há, também, os que relataram ter ingressado nas práticas justamente por não terem recebido um cuidado que julgassem satisfatório para as suas necessidades.

"Eu não dormia, passava a noite acordada. Hoje eu durmo a noite quase toda mesmo (...) quando saí daquele médico [que a 'desenganou'], eu já saí com tanta raiva que já não ia mais nem pros médicos. Fiquei num estresse (...), mas aí eu ia a semana todinha (...) só fazendo Tai Chi: fazia lá na Casa da Cultura, aqui, ali no posto (...) ia todo dia, todo dia. Hoje estou boa, faço tudo, sou uma dona de casa. E eu não fazia nada disso não, passava noites e noites acordada, nem dormia de noite nem nada..." (EI, Tai Chi Pai Lin, atividade interna, unidade P).

A terceira particularidade faz referência à integração dessas práticas a outros recursos do território e ao estreitamento de relações interpessoais.

Modos de apoio à ampliação das redes de convivência e do acesso a bens culturais foram observados em práticas desenvolvidas nesses diferentes espaços. A intenção ao promover esse apoio explicita a compreensão de saúde desses profissionais.

"A experiência aqui [na UBS] é uma amostra do que ela pode fazer lá fora (...) porque o leque corporal é imenso (...) eu gosto muito de dar os endereços dos recursos da comunidade (...) a UBS, ela serve como um espaço de passagem para começar a adotar algum hábito que demora para ser adotado. Porque quem que nunca praticou, não é de repente que vai adotar, por mais que a saúde toda, que o médico fale: 'vai fazer atividade física (...) vai praticar algum esporte': a pessoa tem que pesquisar qual é a sua" ( $\mathrm{Q}$, terapeuta ocupacional, Relaxamento, atividade interna, unidade V). 
Em algumas situações, o acesso a bens culturais foi facilitado pelo próprio contexto de realização dos grupos. Mesmo nessas ocasiões, o trabalho de acompanhar a apropriação desses bens pelos praticantes foi incorporado às práticas por meio de momentos de conversa.

"A praticante relata que está vindo também à Yoga e à Meditação, e que depois que começou a vir para as práticas, fez também o seu cadastro na biblioteca, passou a emprestar livros com frequência e tem gostado de ler" (Roda de Conversa no Lian Gong, biblioteca municipal, unidade S).

$\mathrm{O}$ apoio à criação de laços de convivência foi oferecido intencionalmente em práticas abertas à participação comunitária e caracterizadas pelo emprego de linguagens lúdicas. Nessas ocasiões, as relações entre os praticantes foram favorecidas pela música ou dança, e trabalhadas nos encontros por meio de vivências de sinergia e harmonização intencional de movimentos.

"As Danças Circulares trabalham muito com memória, ritmo, coordenação motora (...) nosso serviço visa muito à inclusão e à convivência (...) a gente percebe pela própria técnica que existe isso, das pessoas cuidarem do outro (...) se as pessoas erram, o outro ajuda, se a pessoa tem dificuldade de locomoção, eles tomam mais cuidado, existe uma integração muito grande (...) tem dias em que o grupo está com mais pessoas com dificuldades, e as pessoas que têm mais facilidade entendem (...) existe muito essa troca, essa compreensão (...) eu acho que a Dança Circular traz muita generosidade entre as pessoas" (AC, educadora de saúde pública, Danças Circulares, centro de convivência, unidade F).

Oportunidades de percepção corporal, exploração das possibilidades de movimento, sinergia com o grupo e sintonia com a música foram observadas também em práticas que abordaram as relações entre saúde, cultura e cidadania; estas se caracterizaram, ainda, por articulações com grupos artísticos e culturais em seus territórios e pelo apoio aos praticantes na apropriação, ou reapropriação, de suas referências identitárias e culturais.

"O grupo começou sendo oferecido pra pessoas com deficiência e familiares (...) sempre esteve presente a ideia da participação da comunidade nesse espaço, para não ser um grupo segregativo [mas] de troca entre pessoas com e sem deficiência (...) a Capoeira é uma prática corporal que, em geral, é muito bem vista pelos jovens, então é esse reconhecimento da comunidade, vendo o grupo quando a gente vai jogar no parque. A partir do momento em que eles apresentam uma outra forma de expressão que é muito reconhecida (...), a gente acha que isso vai dar um outro reconhecimento pra eles também" (F, terapeuta ocupacional, Capoeira, escola pública, unidade Z).

Narrativas de profissionais entrevistados atribuíram a sua produção de práticas tanto nas UBS como em espaços do território às convergências entre seus percursos formativos profissionais e complementares; às iniciativas políticas do município, de formação e educação continuada em PICs; e aos valores e pressupostos do SUS incorporados aos seus trabalhos.

Além desses aspectos, profissionais associaram a diversidade de práticas, bem como o emprego de abordagens de diferentes tradições e repertórios, à intenção de corresponder às necessidades e demandas dos grupos.

A diversidade de raízes culturais nas abordagens foi identificada por meio de narrativas dos profissionais e fragmentos das práticas: Qi Gong, Lian Gong, Tai Chi, assim como Yoga e Meditação, ancorados em sistemas filosóficos próprios; Danças Circulares, com tradições de movimento de vários povos; Capoeira, patrimônio cultural imaterial de raiz afro-brasileira; Bioenergética, associada à contracultura; Calatonia, Eutonia e Método Feldenkrais, criados em resposta a limitações de perspectivas da medicina diante de alguns problemas de saúde.

\section{Discussão}

A opção pela observação de uma única sessão por prática limita a análise a uma perspectiva horizontal e panorâmica do universo pesquisado; e a diversidade de práticas, ambientes e profissionais envolvidos que caracteriza o contexto da pesquisa (Tabelas 1, 2 e 3) inspira o recorte a ser adotado.

As práticas corporais e meditativas têm origem em universos de conhecimento estranhos à racionalidade biomédica, suas concepções e valores; e contrastam com a dualidade corpo-mente epistemologicamente enraizada na medicina ocidental contemporânea 22 , o que requer considerar as limitações de tradução 23 da profundidade desses universos ao se produzir interlocuções com os temas da promoção da saúde. Portanto, a análise é circunscrita às práticas em sua dimensão de trabalho em saúde 24 , com foco nas relações entre suas finalidades e as necessidades e interações dos praticantes. 
A diversidade do elenco de trabalhadores na produção das práticas indica que a amplitude dos saberes envolvidos ultrapassa o campo particular de cada profissão; desta percepção decorre a perspectiva transversal que orienta esta análise.

Cabe também esclarecer que, em relação às melhoras de saúde em si, os resultados encontrados corroboram, em linhas gerais, achados de pesquisas anteriores realizadas com praticantes de perfil semelhante e em unidades públicas de saúde da mesma região 25,26 . Portanto, o que se quer compreender é como isso ocorre, ou seja, o que caracteriza os processos relacionados às melhoras de saúde relatadas, como é detalhado a seguir.

\section{Relações entre as práticas e a construção de referências no cuidado à saúde}

Nas práticas analisadas, o trabalho dos praticantes na construção de suas referências para o cuidado à saúde deu-se principalmente por meio de um processo de refinamento da atenção consigo mesmos.

Para uma leitura desse processo, parte-se da compreensão de que as estruturas socialmente constituídas são também estruturantes das percepções, apreciações e ações dos indivíduos, conforme suas posições e relações sociais; e constituem repertórios que se configuram nos corpos, forjando uma matriz denominada habitus 20. Essa matriz é continuamente atualizada pela experiência e torna-se uma referência útil para responder à maior parte das situações no cotidiano; no entanto, ela pode também mostrar-se insuficiente perante algumas situações mais exigentes, levando os indivíduos à crise. Dessa perspectiva, os relatos sobre as modificações promovidas por praticantes em seus contextos de vida revelaram modos singulares de responder às crises que os levaram a ingressar nas práticas. Seus relatos sugerem também que as transformações empreendidas tiveram por base suas próprias percepções.

Por sua vez, o trabalho de dar suporte aos processos de transformação vivenciados diferenciou-se, em grande parte das situações observadas, de condutas ainda usuais no campo da saúde, orientadas por propostas normativas, de perfil mais vertical e prescritivo, com foco em mudanças de hábitos para a adoção de estilos de vida saudáveis 27.

Boa parte das práticas analisadas teve por foco o potencial dos próprios praticantes, ativado pela experimentação de uma qualidade somática de atenção - se a distinção entre corpo e soma for compreendida com base no ponto de vista do observador, em que corpo está referido à percepção em terceira pessoa, e o soma, ao corpo vivo, percebido em primeira pessoa 28 . Além de ser oportunizada pelas práticas, essa qualidade as extrapolou, dado que a apropriação realizada por cada praticante se tornou recurso próprio, incorporado à sua vida. Identifica-se aqui a aquisição de modos somáticos de atenção 21 , formas de atenção com o corpo e ao próprio corpo, indissociáveis das suas dimensões subjetivas, do meio intersubjetivo em que são vivenciadas e de sua elaboração cultural. Ao potencializar a construção de referências singulares, essa aquisição contribui para a autonomia dos praticantes na promoção, recuperação e manutenção da sua saúde.

A presença dessa qualidade de atenção em práticas de orientação tão diversa possibilitou ainda identificar, para além das características próprias de cada uma delas, sua dimensão de prática social, comprometida com a saúde na vida dos praticantes.

Por outro lado, os problemas identificados em situações em que essa qualidade esteve ausente indicam dificuldades relacionadas à concepção e organização do trabalho em saúde. A atribuição dessa responsabilidade a profissionais sem que seu preparo seja suficiente para contemplar as necessidades dos praticantes e dialogar com suas referências culturais, bem como a carência de supervisão e avaliação, limitaram por vezes a condução das práticas à mera reprodução gestual.

\section{A integração entre promoção e cuidado terapêutico: contribuições e desafios}

A união entre promoção e cuidado terapêutico nas práticas analisadas caracteriza-se pelo estímulo ao potencial de saúde e é um traço comum a outras modalidades de práticas integrativas e complementares 29. Essa característica as aproxima de uma concepção positiva de saúde que, no plano individual, se sustenta na consideração de que "nem todos os sujeitos sadios acham-se isentos de doença [e] nem todos os isentos de doença são sadios" 30 (p. 100); e é particularmente oportuna diante dos desafios implicados na transição epidemiológica e no predomínio das condições crônicas, dado que os sofrimentos mani- 
festados pelos sujeitos que vivenciam estas condições não se enquadram facilmente nas ofertas de cuidado dos serviços, apesar de esforços significativos realizados neste sentido 31 .

Essa aproximação conceitual deve ser compreendida no contexto de transformação do próprio conceito de promoção da saúde que, desde a sua definição como o primeiro dos cinco níveis de prevenção do modelo da história natural da doença, até a sua configuração atual como enfoque político e técnico do processo saúde-doença-cuidado 8 atinge, em sua raiz, o que se entende por saúde. O empenho na construção de um conceito positivo e ampliado de saúde tem como contraparte a necessidade de reconhecimento dos limites de conceitos objetivos de doença e corpo, face à vivência da saúde e do adoecer 27. Desse modo, superar compreensões de corpo reduzidas a aspectos morfológicos e funcionais 27 requer compreendê-lo conectado ao universo de significados e relações que compõem a vida humana.

Deve-se considerar ainda que as interações entre a transformação conceitual em curso e a produção do cuidado são sutis, pois a prevenção e a promoção da saúde são áreas imbricadas, de difícil distinção no âmbito das práticas de saúde; é nesta instância que traços da lógica preventivista se manifestam em recomendações normativas, voltadas às mudanças de hábitos com base nos conceitos de risco e patologia 27 , mas é também aí que se manifesta a tendência às articulações entre saberes técnicos e populares. A incorporação das referidas práticas ao trabalho em saúde no contexto dos serviços desenvolve-se nesse cenário de contradições.

A constatação de que a promoção e o cuidado terapêutico, integrados no interior de cada prática, se apresentaram ora articulados, ora fragmentados em relação às demais ofertas de cuidado, indica não somente que a adoção de diferentes recursos terapêuticos pode trazer ganhos diretos ou resultantes do acompanhamento longitudinal às necessidades de saúde dos praticantes, mas também que a fragmentação produz sofrimento para usuários e sobrecarga para profissionais empenhados na rearticulação de redes de cuidado rompidas. Tanto os ganhos quanto os desafios implicados na produção de um cuidado integrado colocam em evidência a importância da qualidade da comunicação entre seus agentes 32 e a necessidade de valorização das equipes como espaços de intersubjetividade, de diálogo entre as diferentes concepções e abordagens de saúde e de articulação do cuidado.

\section{As práticas e seus contextos: na UBS e no território}

O apoio à ampliação das redes de convivência e à apropriação, por praticantes, de bens culturais e espaços de cidadania - observado tanto em práticas em equipamentos públicos e comunitários quanto no interior de algumas unidades de saúde - é outro indicativo da sintonia de parte dos profissionais com um conceito ampliado de saúde, pautado na valorização da autonomia dos sujeitos quanto aos seus modos de viver 33 .

Essa sintonia foi perceptível na intencionalidade dos profissionais ao promover laços de convivência; ao articular o acesso à cultura e o exercício da cidadania com a saúde; e ao valorizar o diálogo. Observou-se também a convergência de condições que propiciaram essas iniciativas: percursos formativos amplos, que possibilitaram operacionalizar essa perspectiva por meio de repertórios de possibilidades 34 inspirados em diversas racionalidades; o modelo de expansão da política pública municipal, que incorporou as práticas já enraizadas na rede e incentivou novos processos formativos; e os pressupostos do SUS incorporados aos modos coletivos de se operar o trabalho em saúde.

Em diferentes contextos, as práticas se caracterizaram pela função de ponte: ora entre o conhecido e o por conhecer, ora entre o conhecer e o se apropriar; e por vezes entre o se apropriar e o se afirmar nos espaços sociais. Ao mesmo tempo, a interlocução com práticas da mesma natureza produzidas em outros equipamentos sociais dos mesmos territórios esteve ausente na maior parte delas. Essa ausência está possivelmente relacionada com o modo como as necessidades de atenção dos praticantes e o próprio trabalho em saúde são compreendidos e organizados nas unidades de saúde.

Ao se considerar que o trabalho norteado pelo conceito ampliado de saúde requisita a adoção de uma perspectiva intersetorial, é necessário não somente reconhecer as contribuições e limites das práticas analisadas, mas também encorajar a ampliação da interlocução com outros setores para a produção de parcerias. 


\section{Considerações finais}

A originalidade das contribuições das práticas analisadas à promoção da saúde consiste no trabalho com a percepção da unicidade do corpo, como lugar da existência humana singularizada, em permanente relação perceptiva e plural com seus contextos de vida.

A perspectiva holística é expressada nessas práticas pela união entre promoção e cuidado terapêutico. Ponto comum entre elas é a integração entre razão, intuição, sensibilidade e sentidos, baseandose na qual a promoção do autoconhecimento sobressai como recurso para a vida e como base para o exercício do protagonismo, da responsabilidade e da autonomia no cuidado de si.

Por outro lado, a precariedade na integração entre essas práticas e as demais ofertas dos serviços de saúde evidencia a necessidade de se promover parcerias entre os agentes do cuidado, em benefício da saúde de todos os usuários e, especialmente, daqueles que vivenciam condições crônicas. Se a produção de ações multiestratégicas depende do intercâmbio de conhecimentos e práticas, o potencial de contribuição das práticas analisadas é pouco explorado.

A presença das práticas tanto em unidades de saúde quanto em equipamentos do território evidencia a pertinência e, também, as dificuldades em se encontrar caminhos para a construção da intersetorialidade. $\mathrm{O}$ apoio à ampliação das redes de convivência e do acesso a bens culturais, exercido diretamente ou pela função de ponte, contribui à participação social e, indiretamente, ao empoderamento. Mas a falta de interlocução com práticas similares, produzidas por outros atores sociais em espaços dos territórios, faz supor que os limites de uma cultura setorial na saúde prevalecem sobre o trabalho de articulação de parcerias.

Por fim, é importante reconhecer que as práticas corporais e meditativas, como ato técnico e prática social, estão continuamente sujeitas a tendências conservadoras ou transformadoras, portanto, suas contribuições à promoção da saúde dependem do movimento contínuo entre ação, reflexão crítica e formulação de políticas.

\section{Colaboradores}

A. T. C. Galvanese colaborou na produção e análise das informações, na concepção, redação e revisão final do artigo. N. F. Barros contribuiu na redação e revisão do artigo. A. F. P. L. d'Oliveira colaborou na análise das informações, na concepção, redação e revisão final do artigo.

\section{Agradecimentos}

Ao Prof. Dr. Charles Dalcanale Tesser, pelos valiosos comentários. Aos revisores, pelas valiosas contribuições que muito nos auxiliaram no aprimoramento do artigo.

\section{Referências}

1. Organización Mundial de la Salud. Estrategia de la OMS sobre medicina tradicional 20142023. Genebra: Organización Mundial de la Salud; 2013.

2. Departamento de Atenção Básica, Secretaria de Atenção à Saúde, Ministério da Saúde. Política Nacional de Práticas Integrativas e Complementares no SUS - PNPIC-SUS. Brasília: Ministério da Saúde; 2013.

3. Luz MT. Novos saberes e práticas em saúde coletiva. São Paulo: Editora Hucitec; 2003.

4. Sousa IMC, Bodstein RCA, Tesser CD, Santos FAS, Hortale VA. Práticas integrativas e complementares: oferta e produção de atendimentos no SUS e em municípios selecionados. Cad Saúde Pública 2012; 28:2143-54.

5. Ministério da Saúde. Portaria no 2.446, de 11 de novembro de 2014. Redefine a Política Nacional de Promoção da Saúde (PNPS). Diário Oficial da União 2014; 13 nov.

6. World Health Organization. Declaration of Alma-Ata. http://www.who.int/hpr/NPH/ docs/declaration_almaata.pdf (acessado em 14/ Mar/2016). 
7. World Health Organization. Health promotion evaluation: recommendations to policymakers. Report of the WHO European Working Group on Health Promotion Evaluation. Copenhagen: WHO Regional Office for Europe; 1998.

8. Buss PM. Uma introdução ao conceito de promoção da saúde. In: Czeresnia D, Freitas CM, organizadores. Promoção da saúde: conceitos, reflexões, tendências. Rio de Janeiro: Editora Fiocruz; 2009. p. 15-38.

9. Carvalho FFB, Nogueira JAD. Práticas corporais e atividades físicas na perspectiva da promoção da saúde na atenção básica. Ciênc Saúde Coletiva 2016; 21:1829-38.

10. Cardoso R, Souza E, Camano L, Leite JR. Meditation in health: an operational definition. Brain Res Brain Res Protoc 2004; 14:58-60.

11. Schraiber LB. Necessidades de saúde, políticas públicas e gênero: a perspectiva das práticas profissionais. Ciênc Saúde Coletiva 2012; 17:2635-44.

12. Barros NF, Tovey P, Adams J. Investigações qualitativas em práticas alternativas, complementares e integrativas. In: Barros NF, Cecatti JG, Turato ER, organizadores. Pesquisa qualitativa em saúde: múltiplos olhares. Campinas:Editora Unicamp; 2005. p. 219-31.

13. Denzin NK, Lincoln YS. A disciplina e a prática da pesquisa qualitativa. In: Denzin NK, Lincoln YS, organizadores. O planejamento da pesquisa qualitativa: teorias e abordagens. 2a Ed. Porto Alegre: Editora Artmed; 2006. p. 15-41

14. Paganizzi L. Los medios en T.O. In: Paganizzi L, editora. Terapia ocupacional: del hecho ao dicho. Buenos Aires: Psicoterapias Integradas Editores; 1991. p. 57-64.

15. Geertz C. A interpretação das culturas. Rio de Janeiro: LTC; 2008.

16. Nicolau SM. Grupos na atenção básica: enraizar-se em uma comunidade. In: Maximino V, Liberman F, organizadoras. Grupos e terapia ocupacional: formação, pesquisa e ações. São Paulo: Summus Editorial; 2015. p. 264-74.

17. Schraiber LB. Pesquisa qualitativa em saúde: reflexões metodológicas do relato oral e produção de narrativas em estudo sobre a profissão médica. Rev Saúde Pública 1995; 29:63-74.

18. Jiménez IV. La entrevista en la investigación cualitativa: nuevas tendencias y retos. Revista CAES 2011; 31:119-39.

19. Critelli DM. Analítica do sentido: uma aproximação e interpretação do real de orientação fenomenológica. São Paulo: EDUC/Editora Brasiliense; 1996.

20. Bourdieu P. A economia das trocas simbólicas. São Paulo: Perspectiva; 2011.

21. Csordas TJ. Corpo/significado/cura. Porto Alegre: Editora UFRGS; 2008.
22. Czeresnia D. Categoria vida: reflexões para uma nova biologia. São Paulo: Editora da Unesp/Rio de Janeiro: Editora Fiocruz; 2012.

23. Pereira PPG. De corpos e travessias: uma antropologia de corpos e afetos. São Paulo: Annablume; 2014

24. Mendes-Gonçalves RB. Práticas de saúde: processos de trabalho e necessidades. São Paulo: Centro de Formação dos Trabalhadores em Saúde, Secretaria Municipal da Saúde de São Paulo; 1992. (Cadernos CEFOR Série Textos, 1)

25. Busato S, Tanaka ECM, Santos AS, Higuchi TE, Leite JR, Kozasa EH. Traditional and integrative medical practices in public health services in the Downtown-West region of the city of São Paulo, Brazil, and their relation to health promotion. J Altern Complement Med 2008; 14:1071-4.

26. Higuchi TE, Kozasa EH, Santos TM, Oi LL, Garcia MC, Silva AL. Avaliação qualitativa das práticas meditativas oferecidas no sistema público de saúde na Coordenadoria Regional de Saúde Centro-Oeste (CRSCO) em São Paulo. Saúde Colet 2011; 8:230-3.

27. Czeresnia D. O conceito de saúde e a diferença entre prevenção e promoção. In: Czeresnia D, Freitas CM, organizadores. Promoção da saúde: conceitos, reflexões, tendências. Rio de Janeiro: Editora Fiocruz; 2009. p. 39-53.

28. Hanna T. What is somatics? Part I. Somatics: Magazine-Journal of the Bodily Arts and Sciences 1986; 5:4-8.

29. Tesser CD. Práticas complementares, racionalidades médicas e promoção da saúde: contribuições pouco exploradas. Cad Saúde Pública 2009; 25:1732-42.

30. Almeida Filho N. Holopatogênese: esboço de uma teoria geral de saúde-doença como base para a promoção da saúde. In: Czeresnia $\mathrm{D}$, Freitas CM, organizadores. Promoção da saúde: conceitos, reflexões, tendências. Rio de Janeiro: Editora Fiocruz; 2009. p. 97-115.

31. Conselho Nacional de Secretários de Saúde. A atenção primária e as redes de atenção à saúde. Brasília: Conselho Nacional de Secretários de Saúde; 2015.

32. Peduzzi M. Equipe multiprofissional de saúde: conceito e tipologia. Rev Saúde Pública 2001; 35:103-9.

33. Campos GW, Barros RB, Castro AM. Avaliação de política nacional de saúde. Ciênc Saúde Coletiva 2004; 9:745-9.

34. Liberman F. Delicadas coreografias: instantâneos de uma terapia ocupacional. São Paulo: Summus Editorial; 2008. 


\section{Abstract}

The article presents an analysis of contributions and challenges associated with bodily practices and meditation for health promotion in the public primary care system. The qualitative study was developed in 16 healthcare units in the city of São Paulo, Brazil, using interviews with 29 health professionals and 36 practitioners of bodily practices and meditation, including participant observation of 31 practices such as Tai Chi, Lian Gong, Qigong, Yoga, Capoeira, Dance, Meditation, Relaxation, Mindfulness, and Body Awareness. There was an improvement in joint pain, mobility, balance, memory, depression, and anxiety, besides greater ease in coping with chronic conditions. Such contributions are related to favoring practitioners' autonomy, building health references through self-awareness; the combination of health promotion and therapeutic care in the approaches; and support for access to cultural goods and community spaces. The challenges identified here were precarious integration with the supply of other health services, lack of supervision and evaluation, and the predominance of a health-sector culture.

Health Knowledge, Attitudes, Practice; Complementary Therapies; Meditation

\section{Resumen}

El artículo presenta un análisis de las contribuciones y los desafios de las prácticas corporales y meditativas a la promoción de la salud en la red pública de atención primaria. La investigación cualitativa se desarrolló en 16 unidades de salud del municipio de São Paulo, Brasil, mediante entrevistas de 29 profesionales y 36 practicantes, $y$ una observación participante de 31 prácticas, entre Tai Chi, Lian Gong, Qi Gong, Yoga, Capoeira, Bailes, Meditación, Relajamiento, Consciencia y Percepción Corporal. Hubo una mejora de los dolores articulares, movilidad, equilibrio, memoria, depresión y ansiedad, y mayor facilidad al lidiar con condiciones crónicas. Tales contribuciones se relacionan con el favorecimiento de la autonomía de los practicantes, por la construcción de referencias de salud mediante el autoconocimiento; a la unión entre promoción y cuidado terapéutico en los enfoques; $y$ el apoyo al acceso a bienes culturales y espacios de ciudadanía. Los desafíos identificados son la precariedad en la integración con las demás ofertas de los servicios de salud, la carencia de supervisión y evaluación, así como el predominio de una cultura sectorial en la salud.

Conocimientos, Actitudes y Práctica en Salud; Terapias Complementarias; Meditación
Recebido em 11/Jul/2016

Versão final reapresentada em 03/Fev/2017

Aprovado em 20/Fev/2017 